ANNALS, AAPSS, 520, March 1992

\title{
Literacy Acquisition in Peru, Asia, and the United States
}

\author{
By HAROLD W. STEVENSON and CHUANSHENG CHEN
}

\begin{abstract}
An important question in the study of literacy is the degree to which environmental conditions influence children's ability to learn to read. A comparison was made of the reading ability of schooled and nonschooled children in three locations in Peru: the city, the highlands, and the rain forest. Increased attendance resulted in improved reading ability, but the degree of improvement varied according to the environments in which the children resided. When the children were followed up nine years after the original testing, they showed continued improvement in reading ability, especially in the environment where economic conditions had improved. A comparison of the Peruvian children with children in three industrialized societies, Japan, Taiwan, and the United States, revealed little difference in the children's cognitive abilities but great differences in their reading ability. More stimulating environmental conditions and better schooling in the industrialized societies were presumably responsible for these differences.
\end{abstract}

Harold W. Stevenson is professor of psychology at the University of Michigan. He received his M.A. and Ph.D. at Stanford University. His primary areas of research are in children's learning and cognitive development and, in particular, the effect of cultural factors on children's academic achievement.

Chuansheng Chen, a native of China, is a doctoral candidate in Michigan's Department of Psychology. He received his B.S. from Hangzhou University and his M.A. from the University of Michigan. He has been involved in comparative study of children's academic achievement for the past several years. 
$\mathrm{R}^{\mathrm{R}}$

ARELY are there occasions in industrialized societies when we can compare the reading achievement of children who do attend school and children who do not. Yet many questions concerning the acquisition of literacy depend on such comparisons. We know that the operations of mathematics can be acquired without going to school, ${ }^{1}$ but we have little information about the degree to which children can also learn to read without formal academic instruction. Most urban children encounter written language every day in road signs, billboards, displays in stores, books, television, and newspapers. Do encounters with these stimuli serve to provide children with the fundamentals of literacy? How about children living in remote rural areas of developing countries, where children seldom, if ever, encounter written language in their everyday lives? Is formal schooling their only avenue to literacy?

The effects of schooling on children's academic achievement in industrialized societies have been studied in great detail, and from studies in developing countries we know something about the effects of such factors as the availability of textbooks, class size, and teachers' salaries on children's scholastic performance. ${ }^{2}$ Seldom, however, have

1. Terezinha N. Carraher, David W. Carraher, and Annalucia D. Schliemann, "Mathematics in the Streets and in Schools," British Journal of Developmental Psychology, 3:21-29 (1985).

2. Bruce Fuller, "What School Factors Raise Achievement in the Third World?" Review of Educational Research, 57:255-92 (1987); Stephen P. Heyneman and William A. Loxley, "The Effect of Primary School Quality the studies in developing countries investigated how the effects of schooling are influenced by such potentially important variables as the experiences available in children's everyday environment, the cognitive stimulation provided by the home, and efforts by parents to teach their children to read. These factors are of special interest when one considers that children have opportunities out of school to acquire some of the information and skills taught in school and that the effects of schooling may be decreased when both schooled and nonschooled children live in stimulating and informative environments.

The questions we asked in our research concern the relationship of literacy to the environments in which children live. We chose several markedly different environmental settings to evaluate these effects. In an initial study, we compared the performance of schooled and nonschooled children in three regions of Peru: the city, remote villages in the Peruvian highlands, and isolated villages in the Peruvian rain forest. Nearly a decade later we returned to these locations in an effort to find out as much as possible about what changes had occurred in the lives of the individuals and how these changes might have influenced their level of literacy. Following our initial study, we conducted a study with children living in large cities in three highly industrialized societies: Japan, Taiwan, and the United States. A comparison of the performance of children in these societies with that of the Peruvian

on Academic Achievement across Twenty-Nine High and Low Income Countries," American Journal of Sociology, 88:1162-94 (1983). 
children offered us additional information about how environmental conditions may facilitate or limit the degree to which young children acquire literacy.

\section{PERU}

The diversity of environments and the opportunity to compare the achievement of schooled and nonschooled children make Peru an appealing country in which to study the acquisition of literacy. Peru is a developing country with a long and illustrious cultural history. The indigenous population of Quechuaspeaking Indians is composed of descendants of the Incas, who once governed an empire of millions from their highland capital in Cuzco. As in many Latin American countries, however, life in Peru has been dominated by mestizos-persons of mixed Spanish and Indian heritage-for over four centuries.

The population of the highlands is still predominantly Quechua speaking, but the number of Quechua speakers in the capital city of Lima has increased during the past several decades due to the migration of many families from the highlands. Squatter settlements housing millions of people now cover the outskirts of the city. As might be expected in a country that has faced intractable economic problems, many families in Peru are unable to send their children to school. At the time of our study, only 53 percent of the general population of Peru enrolled their children in school at the appropriate age, despite the fact that elementary education is compulsory. The per- centage of Quechua children attending school is undoubtedly even lower.

We selected three locations in Peru for our study of Quechua children and their families: the highlands, Lima, and the selva (rain forest) area of northeast Peru.

\section{Highlands}

In the highlands we chose the region of Andahuaylas, an area from which residents have migrated to both the city and the selva. Families have lived in Andahuaylas for many centuries, and they have maintained their traditional cultural values, the Quechua language, and their own style of dress. Because it has become increasingly difficult in recent years to make even a subsistence living, many families from this region have migrated to Independencia, one of the squatter settlements in Lima that we selected as our second research site.

\section{Lima}

Inhabitants of the pueblos jóvenes, the "new cities" of the squatter settlements, live under very difficult conditions. Neighborhoods are relatively stable near the roadways, but as one climbs the rocky hills of Independencia, the construction of the homes becomes more flimsy, the population becomes more transient, and living conditions become more primitive. Migrants to the city must adapt to the urban mestizo culture. This means that they must abandon Quechua and learn Spanish, and replace their traditional garments with Western clothing. 


\section{Selva}

Hundreds of kilometers northeast of Cuzco is Lamas, a region of the selva to which descendants of a group of Chancas migrated from the highlands over 500 years ago after their defeat in a battle with the Incas. Chancas have not intermarried with mestizos or other Amazonian Indian groups. They are farmers, and, in this mestizo-dominated region, they have been forced to establish their plots of land for farming deep within the rain forests. This means that they must leave their villages during the week, returning only on weekends. Children typically remain in the villages, tended by their older siblings and a few village elders.

All of the Quechua are poor, but poverty is most severe in the selva. The modern world is immediately available to anyone who takes the bus from the squatter settlements to downtown Lima, but Quechua homes of the selva have no electricity, and few persons in Lamas have ever seen a television set or a motion picture. Children in the selva suffer from poor nutrition, for in the barter economy of the region the more desirable foodstuffs are exchanged for clothing and implements. Similarly, the poverty of the region has resulted in schools that are housed in small, crowded buildings often lacking a blackboard or sufficient desks for the students. In Lima, schools in the pueblos jóvenes may have broken windows and some classrooms may lack a roof, but the supplies and equipment are superior to those in Lamas. Andahuaylas stands between Lima and
Lamas in the quality of the physical environment provided for children.

\section{The children}

We studied over a thousand children: 387 from Lima, 428 from Andahuaylas, and 336 from Lamas. There were 6- to 8-year-olds-"younger children"-who had not attended school or who were enrolled in first grade, and 9- to 12-year-olds-"older children"-who had not attended school or who were enrolled in first, second, or third grade. In each location, the two groups-nonschooled and enrolled in first grade- of younger children had approximately the same chronological age, as did the four groups-nonschooled and enrolled in first, second, or third grade- of older children.

We tested children from all of the schools we could find in each location. Our procedure for locating children who did not attend school was to send a person to the neighborhoods or villages. This scout sought out families with a child of the proper age and attempted to arrange for the child's participation in the study.

Practically no children refused to cooperate or wanted to leave once testing began. They had never participated in an experience like the one we provided. They were fascinated by the bright and interesting materials that had been constructed for the study, and they enjoyed interacting with an attentive and responsive adult. Their interest was also maintained by the trinkets and snacks given during the testing. 


\section{READING ACHIEVEMENT}

We had to devise our own test of reading achievement. Although there was a movement about twenty years ago to introduce Quechua as the language of instruction in the highlands, none of the textbooks or teaching materials used in the schools we visited were in Quechua. Because the textbooks and reading instructions were in Spanish, the reading test was written in Spanish. We based our test on an analysis of the content of the textbooks used in Peruvian elementary schools, our own experience in Peru, and on discussions with Peruvian colleagues.

The test required children to read letters and words, to select pictures described by words, and to answer questions about what they had read. The words ranged from easy ones, such as dos, sol, and dia, to more complex ones such as maestro, hermano, and horizonte. Our test of reading comprehension had two parts. In the first, the children were asked to read a word or words aloud and to select one of three pictures that best described what had been read. For example, an easy item included the word "girl" and three line drawings depicting a boy, a girl, and a knot. The most difficult item included the phrase "two people dancing while the children watch"; three drawings depicted adults dancing with children watching, adults dancing without children watching, and adults working while children watched. In a final part of the test, children read short paragraphs about which they later were asked several questions.
We found that the younger nonschooled children in Andahuaylas and Lamas were illiterate. They apparently had little opportunity either within or outside their homes to learn even a few letters of the alphabet. In Lima, the younger nonschooled children had learned a few letters and the older nonschooled children knew many letters and a few words. Only in Lima, therefore, had nonschooled children-even those as old as 12 acquired the fundamental components of reading.

Attending school had vastly different effects, depending upon where the children lived. Children who were enrolled in the first grade in Lamas and Andahuaylas showed very little benefit from their instruction. They were able to answer fewer than 15 percent of the questions asked on the test. Schooling had a much greater effect in Lima, where both younger and older first-graders were able to read and understand some of the words on the test.

The children's reading skill improved with increased attendance at school, but the increase was not equivalent in the three locations. Children in Andahuaylas were consistently one year behind the children in Lima in their reading skill, and children in Lamas were about two years behind. In other words, third-graders in Lamas and secondgraders in Andahuaylas were reading little better than Lima firstgraders.

The finding that very few of the nonschooled children were able to read reflects the fact that reading skill requires more than facility with the spoken language. In fact, whether 
or not the children were able to speak Spanish had no relation to their reading scores. If reading skill were strongly dependent upon the language spoken at home, the schooled children of Lamas, who speak Spanish at home, should have shown less difficulty in learning to read Spanish words than the children from the Quechua-speaking families of Andahuaylas. This was not the case.

In addition to the general environmental differences in the three locations, there were also indications that the home life of the children in the three locations differed greatly. We obtained information about the children's everyday home environments from interviews with the children's parents.

Most of the parents had little education. Fathers in Lima had attended school an average of 4.9 years; the average was 2.7 in Andahuaylas and 1.9 in Lamas. The corresponding values for the mothers were $2.2,0.7$, and 0.1 years, respectively. Thus it is doubtful that most parents provided their children with a highly literate environment at home.

A direct index of the stimulation offered by the home was based on a question in which we asked about what the parents had attempted to teach their children. We asked about 8 activities: numbers, colors, letters, money, the seasons, riddles, Spanish, and games. We also asked whether they read to their child and whether they told their child stories. The mean number of positive responses was 6.5 in Lima, 4.5 in Andahuaylas, and 5.5 in Lamas.

The quality of a home environment depends, in part, on the mate- rial wealth of the family, such as books or toys. We asked about 10 items of material wealth: electricity, radio, television, newspapers or magazines, books, machines, children's books, pictures, toys, and portraits. Each family was given a value between zero and 10, depending on how many of these items they possessed. According to this index, homes in Lima provided children with the greatest opportunities to encounter items that might be helpful to them in learning how to read, and the homes in Lamas, the fewest. The mean number of items in the Lima homes was 4.7; in Andahuaylas, 3.8; and in Lamas, 1.9.

Except for the data related to parental involvement in teaching, these data support the impression that children in Lamas experience a much more severely deprived environment than do children in Andahuaylas or Lima. Their remoteness from cultural activities that might help them in learning how to read, the lack of physical resources in the home, and the low levels of education of their parents were likely contributors to their poor reading skill.

\section{FOLLOW-UP STUDY}

Our experiences in Peru did not end with the completion of the original study. Nine years after the testing was completed, we decided to initiate a follow-up study to evaluate the ultimate educational outcomes for these three groups of Quechua children. We returned to Independencia, Andahuaylas, and Lamas and attempted to locate our original subjects. In view of the high mobility of 
these families, we were reasonably successful; we were able to interview and test approximately one-third of the subjects in each location: 141 in Lima, 165 in Andahuaylas, and 89 in Lamas.

There is always a worry in followup studies that the persons who can be located are not representative of the original sample. We were able to test this possibility by comparing the reading scores from the original testing of the subjects we were able to locate with those of the remainder of the original sample. The average score for the two groups differed by only 0.8 of a point. Parental educational level and quality of the home environment did not differ significantly between members of the follow-up sample and the remaining subjects.

We increased the difficulty of the reading test for the follow-up sample by adding more difficult words to the test and by increasing the length and complexity of the text material. The most difficult items on the test were ones that an average fifth-grader should be able to read and understand.

As might be expected, reading scores improved over the nine-year period that separated the original and follow-up testing. Scores for the three locations did not differ greatly from each other on the second testing; they ranged from 85 percent to 92 percent correct response to the original test items, and from 77 percent to 83 percent correct response to the items on the total test. There was no indication of a loss in literacy after leaving school, a finding in line with similar results reported by Wagner and his colleagues for children in Morocco. ${ }^{3}$

The residents of Lamas made the greatest gains between the two testing periods. We believe that the large improvement reflects the remarkable changes during the past decade in the economy of the selva. The highly profitable cocaine trade is centered in the northeast section of Peru. Tobacco fields have been replaced by coca plants, and residents of Lamas have benefited from the flourishing business of processing of cocaine. The gain in the economic status of residents of Lamas is reflected in the increased attendance at school. The individuals we followed up in Lamas had attained an average of 5.3 years of education. This is a remarkable gain for Lamas, for the difference between the levels of education of the children and of their fathers was 3.4 years. The improvement in the economy of Lamas was also evident in the increased number of material possessions in the Lamas households. For example, in the original study, only 27 percent of the Lamas households possessed a radio; nine years later, 73 percent owned a radio. This percentage compares favorably with the 99 percent of the families in Lima and the 71 percent in Andahuaylas who owned a radio. Similarly, half of the families in Lamas visited in the follow-up study owned books, compared to 30 percent in Lima and 21 percent in Andahuaylas. The earlier deficiencies of the children of Lamas were

3. Daniel A. Wagner et al., "The Myth of Literacy Relapse: Literacy Retention among Moroccan Primary School Leavers," International Journal of Educational Development, 9:307-15 (1989). 
lessened, therefore, by their greater opportunities to attend school and by marked improvements in their daily environments.

\section{COMPARISONS WITH \\ CHINESE, JAPANESE, AND AMERICAN CHILDREN}

Shortly after we completed our first study in Peru, we began a study in Japan, Taiwan, and the United States that also included a test of reading ability. Regardless of the language being read, a reading test must include an evaluation of children's knowledge about the fundamental components of the written language and the children's comprehension of text. The test that we constructed for this later study was very similar to the one used in Peru. It contained sections that required the child to read letters of the alphabet in English (hiragana, in Japanese, and zhuyin fuhao, in Chinese) and words in English and characters in Chinese and Japanese. As in the Peruvian test, children were given words or short phrases that described the appropriate choice of one of three accompanying pictures.

The reading tests were given to 240 children randomly selected from 20 representative first-grade classrooms in each of three cities: Minneapolis, Minnesota; Sendai, Japan; and Taipei, Taiwan.

Differences between the reading skill of the first-graders in Peru and those in the three other locations were very great. Nearly every child in Taipei, Sendai, and Minneapolis knew all of the letters (hiragana, zhuyin fuhao); none of the three groups of
Quechua children had learned even half of them (see Figure 1). Differences were equally dramatic for the portion of the test requiring the child to read words and to demonstrate comprehension of their meaning.

American and Asian children's scores for comprehension were higher than those for reading words. This may indicate that they were aided in reading by the presence of pictures depicting what was described in the word or phrase. For example, seeing a rainbow in one of the drawings may be of help in recognizing the word "rainbow." Quechua children apparently found these cues to be of little help.

We can suggest two hypotheses to account for these startling differences in children's achievement. The first suggests that environmental conditions, both at home and at school, facilitate learning how to read to a much greater extent in the three industrialized societies than in the Quechua societies. The second suggests that Quechua children simply may not have attained the level of cognitive development necessary to benefit readily from the kinds of opportunities they are provided.

The close interaction between environmental conditions and intellectual functioning makes it impossible to isolate the independent contribution of each. Nevertheless, it would be of interest to compare the cognitive functioning of young children in these diverse environments. Fortunately, information was available from the two sets of studies to make several comparisons possible.

In addition to the reading test, each Quechua child was given a bat- 
FIGURE 1

DIFFERENCES IN READING SKILLS

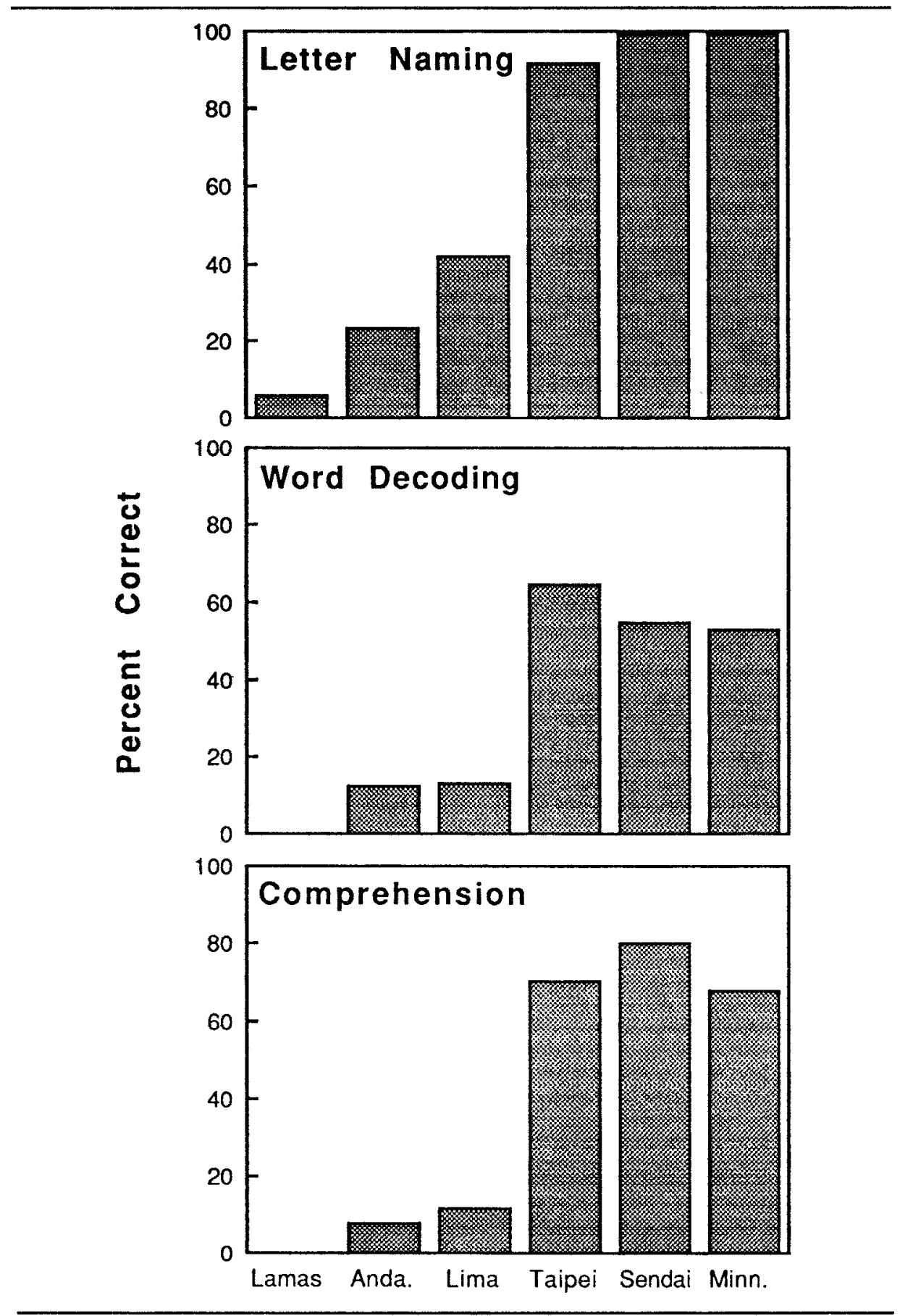


tery of cognitive tasks that contained tasks of the types typically found in tests of intelligence. Among these were tests of general information, story memory, and auditory memory. The general-information tests contained questions whose answers are not directly taught in school but are part of common knowledge. Easy items involved telling how many paws a dog has; more complicated ones required naming things a plant needs in order to grow and explaining why people cannot live under water. In the story-memory test, the children listened to a brief story and then were asked questions about its content. In the auditory-memory test, the children were asked to repeat a pattern of taps separated by short (S) and long (L) pauses. The patterns ranged from simple ones consisting of a sequence of two taps, such as SL, to much more complex ones, such as SSLSLSS.

Children were tested by examiners who were fluent in the child's preferred language, Quechua or Spanish. Over 75 percent of the children in Andahuaylas were tested in Quechua, and nearly every child in Lima was tested in Spanish. In Lamas, the language of testing depended on the child's status in regard to schooling; nearly all of the children who attended school were tested in Spanish, but approximately half of the children who did not attend school were tested in Quechua.

The results were surprising. Children of Andahuaylas and Lima demonstrated no deficiencies in cognitive functioning (see Figure 2). They generally obtained scores on the cognitive tasks that were equivalent to those of the Chinese, Japanese, and American children. Children in Lamas received somewhat lower scores than the other groups on general information and story memory, the two tasks requiring verbal response, but even on these tasks the departure of their scores from those of the Chinese, Japanese, and American children was much less dramatic than was the case for the reading scores. Children in Minneapolis received higher scores than the other groups on the two verbal tasks. We believe that the Minneapolis firstgraders did well on these tasks because of the greater tendency of the American than of the Chinese and Japanese mothers to read to their young children, engage them in social conversation, and take them on excursions. ${ }^{4}$ All of these activities are ones that would help the children develop verbal skills and build up a fund of general information.

There is little evidence, therefore, that the slower acquisition of reading skills by the first-graders in Peru was a consequence of deficits in intellectual functioning. Rather, it seems likely that the slowness with which they progressed in learning how to read was due to the inability of their parents and teachers to provide them with an environment conducive to learning how to read and with instruction that was comparable to that experienced by children in the industrialized societies of Japan, Taiwan, and the United States.

4. Harold W. Stevenson et al., "Contexts of Achievement: A Study of American, Chinese, and Japanese Children," Monographs of the Society for Research in Child Development, 55(1-2) serial no. 221 (1990). 
FIGURE 2

DIFFERENCES IN COGNITIVE SKILLS

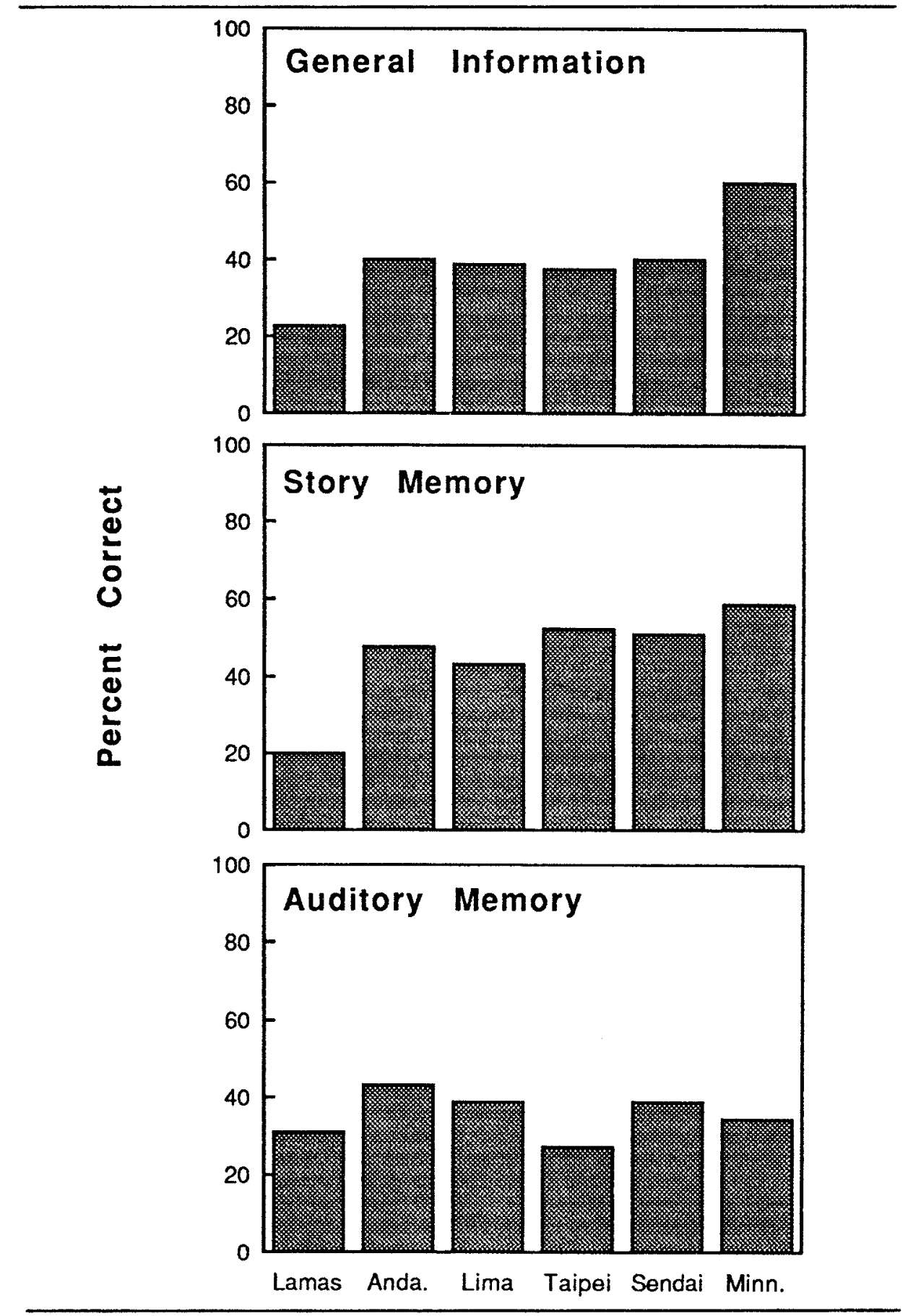




\section{CONCLUSION}

Literacy depends on education; it is not something that is readily acquired outside of school. Unlike the skill in mathematics demonstrated by many uneducated persons, ${ }^{5}$ we have found little indication that children learn to read more than some of the alphabet and a few words when they are poor, live in families with low levels of education, and spend their days in disadvantaged environments.

Parents were correct in assuming that opportunities in the city for learning would be greater than in their native villages. Whether or not the children went to school, their reading ability benefited by the city environment. Even in the city's impoverished pueblos jovenes it was possible to attract better teachers and to provide better conditions for learning than in the villages of the highlands or the selva. The worst conditions existed in the selva, where there were fewer opportunities in the home, in the everyday environment, and in school to encounter circumstances that would be helpful in gaining literacy.

Children in all three locations gained in their reading ability over the nine-year period between the original and final testing, but the most

5. Carraher, Carraher, and Schliemann, "Mathematics in the Streets and in Schools." notable gains were made by the children in the selva. These children demonstrated that with an improved environment, presumably better teachers, and a longer time in school, they could attain reading scores equivalent to those of the children in the city. Results from the cognitive tests reinforced the assumption that the poor performance of children in the original testing was due to the situations in which the children lived, rather than to cognitive inadequacies.

Conditions in Peru are similar to those in many developing countries of the world: poverty, bilingualism, and an indigenous and an imposed culture. All of these factors have combined to make the recent decades among the most tumultuous since the time of the Spanish conquest. The large migration to the city has been motivated by the poor economic conditions in the highlands but also by the desire of parents to improve their children's opportunities for education.

To the degree that parents in the countryside are motivated to move to the city because of educational opportunities for their children, an improvement in schools in the countryside should stem such migration. It seems unlikely, however, that there will be advances in either urban or rural schools of developing countries without a strengthening of the economic conditions of these countries. 